T Revista del instituto de ciencias jurídicas $\int \begin{aligned} & \text { DE PUEBLA, MÉXICO, ISSN: } 1870-2147 \text {. AÑO VI } \\ & \text { NO. 30, JULIO-DICIEMBRE DE } 2012 \text {, PP. 7-34 }\end{aligned}$

\title{
¿Cómo realizar elecciones inauténticas sin morir en el intento? El caso de México y su sistema electoral ${ }^{*}$ \\ How to hold unauthentic elections without dying in the process? The case of Mexico and its electoral system
}

\section{César Cansino**}

\section{RESUMEN}

Si hay un caso en el mundo que por si solo haya implementado y perfeccionado todas las modalidades posibles e imposibles de elecciones inauténticas, ese caso es sin duda México. Parte de la explicación de ello se encuentra en el sistema electoral mexicano, diseñado para que reine la discrecionalidad sobre el imperio de la ley. En este estudio se analiza el fenómeno con los fallos que al cobijo de la ley realizó el Tribunal Electoral del Poder Judicial de la Federación en ocasión de los comicios federales de 2009. Pero el ejercicio aplica perfectamente para los comicios de 2012, pues a final de cuentas la ley electoral sigue siendo la misma.

PALABRAS CLAVE: Elecciones, elecciones inauténticas, México, sistema electoral mexicano, reforma electoral, democracia, Estado, ley electoral.

\begin{abstract}
If there is a single case in the world that has been implemented and perfected under all possible and impossible ways in order to orchestrate unauthentic elections, this case is definitely the Mexican case. Part of the explanation for this lies in the Mexican electoral system, designed to rein discretion over the rule of law. This study analyzes the phenomenon, the failures within the shelter of the law made by the Electoral Tribunal of the Judicial Power of the Federation throughout the 2009 federal elections. However, this exercise applies perfectly to the elections of 2012, because in the end, the electoral law remained the same.
\end{abstract}

KEY WORDS: Elections, unauthentic elections, Mexico, Mexican electoral system, electoral reform, democracy, state, electoral law.

\footnotetext{
* Recibido: 22 de julio de 2012. Aceptado: 15 de septiembre de 2012

* Catedrático-investigador en la Facultad de Derecho y Ciencias Sociales de la Benemérita Universidad Autónoma de Puebla y del Instituto de Ciencias Jurídicas de Puebla, México (politicaparaciudadanos@gmail.com).
} 
CÉSAR CANSINO

\section{Sumario}

1. Introducción

2. Argumentos para una tesis

3. Consideraciones generales sobre el marco legal del sistema electoral mexicano

4. Los fallos del tepJf en el marco de la democracia electoral realmente existente

5. Los fallos del TEPJf en el marco de una situación democrática ideal

A) Neutralidad de los partidos

B) Libertad de expresión

c) Libertad del sufragio

D) Equidad de la contienda

6. A manera de conclusión

\section{Introducción*}

Si hay un caso en el mundo que por sí solo haya implementado y perfeccionado todas las modalidades posibles e imposibles de elecciones inauténticas, ese caso es sin duda México. Sin exagerar, resultaría incompleto un estudio sobre conceptos e índices de integridad electoral si no se considerara como anti-ejemplo de una democracia auténtica al caso mexicano.

Como es sabido, las elecciones en México han sido a lo largo de su historia instrumentos del poder para legitimar dictaduras disfrazadas de democracia. Con todo, después de siglos de tiranías y democracias de fachada, el país comenzó una nueva era democrática a partir de la histórica alternancia de 2000. La derrota en las urnas del otrora "partido oficial", el inefable Partido Revolucionario Institucional (PRI), que gobernó ininterrumpidamente por setenta años, era una razón más que convincente para pensar que los procesos electorales habían conquistado finalmente una condición democrática auténtica, después de años de reformas electorales limitadas y controladas. Sin embargo, después de doce años de alternancia debemos concluir, con más realismo que optimismo, que tales avances fueron insustanciales, al grado que se han reeditado todo tipo de sospechas y dudas acerca de la autenticidad de las elecciones, como en los comicios federales de 2006 y 2012, ambos severamente cuestionados por prácticamente la mitad de la población.

En particular, las elecciones de 2012 presentaron todo tipo de irregularidades y violaciones a los derechos humanos, como la compra y coacción del voto, recuentos dudosos de los votos, discrecionalidad y parcialidad de los árbitros electorales, registros de votantes inexactos, uso de encuestas con fines propa-

* El autor agradece los comentarios de Samuel Schmidt y Juan Campillo, y su autorización para integrarlos al texto. 
gandísticos, campañas mediáticas orquestadas desde el poder para favorecer a unos y perjudicar a otros, falta de seguridad en las boletas ausentes, votos anulados sin justificación, etcétera. Fueron tantas y tan groseras las evidencias de irregularidades que por momentos México parecía instalado de nuevo en la era de la dictadura perfecta del PRI. Lo interesante a considerar en todo caso es que no obstante la inautenticidad de estos comicios y la evidencia fehaciente de todo tipo de irregularidades, al final no pasó nada. El fallo electoral se consumó sin mayores sobresaltos y en las mejores condiciones para los gobernantes y sus cómplices. Tal parece entonces que la viabilidad de las elecciones inauténticas no depende solamente del empleo adecuado de prácticas fraudulentas e impositivas de todo tipo, sino también de la capacidad de maniobra y persuasión de los operadores políticos gubernamentales para hacer aparecer mediáticamente como normal y correcto lo que en realidad fue todo lo contrario.

En suma, la tesis que trataré de defender en este artículo a partir de considerar el caso mexicano es que la viabilidad de una elección inauténtica no depende tanto del tamaño del fraude o de la astucia para encubrirlo, sino de la capacidad de los árbitros y jueces electorales para hacer pasar las irregularidades como normales e insustanciales, y a las elecciones como correctas, cobijados en una ley electoral diseñada especialmente para ello.

\section{Argumentos para una tesis}

Antes que nada debo advertir que mantengo una posición crítica con respecto a la legislación vigente en México en materia electoral, producto de las reformas aprobadas en 2007 tanto a la Constitución como a la ley secundaria respectiva (el Código Federal de Instituciones y Procedimientos Electorales, COFIPE). Mi posición crítica no se circunscribe a los cambios que por efecto de dichas reformas tuvieron lugar en la legislación, sino que mi insatisfacción es más bien con toda la normativa electoral tal y como ha sido diseñada e instituida antes y después de esta última reforma. En mi opinión, nunca hemos contado, ni antes ni ahora, con una legislación electoral a la medida de las exigencias y necesidades de una democracia moderna. Más aún, soy de los que consideran que las reformas electorales más recientes representan en muchos de sus contenidos un retroceso respecto de reformas precedentes, al grado de que nuestra legislación electoral actual no soporta la prueba de una confrontación somera con otras legislaciones equivalentes en el mundo, pues quedaría inmediatamente exhibida en sus muchas contradicciones e inconsistencias. ${ }^{1}$

\footnotetext{
1 Mi posición puede documentarse en Cansino, C. El evangelio de la transición y otras quimeras del presente mexicano, Debate, México, 2009, en especial el capitulo ix: "Claroscuros de una reforma".
} 
En ese sentido, considero que las controversias que en materia electoral ha debido resolver el Tribunal Electoral del Poder Judicial de la Federación (TEPJF), en ocasión de los comicios federales de 2009, nacen de las debilidades de la propia legislación; o sea que se deben más a las ambigüedades normativas que a prácticas claramente contrarias a los principios de una democracia por parte de los involucrados y/o querellados, por más que nuestra legislación las tipifique como tales. Considero incluso que la sola existencia de tales disputas legales -como las que analizaré aquí-si algo pone en evidencia es la apremiante necesidad de una nueva reforma electoral, siempre y cuando se pondere en su confección una perspectiva de más largo alcance y de mayor integralidad que la que ha prevalecido hasta ahora. Y si bien esta consideración es secundaria para evaluar la actuación del TEPJF a la hora de fallar ciertas impugnaciones o presuntas violaciones a la ley, pues la función de este órgano es simplemente garantizar que la ley se aplique de manera correcta y expedita, independientemente de las aberraciones de la propia ley, no deja de ser interesante, pues revela que el problema de las controversias legales es más bien estructural. ${ }^{2}$

De entrada, toda legislación que, como la electoral, admite múltiples interpretaciones e impele a la autoridad judicial respectiva a intervenir excesivamente en su interpretación con vistas a resolver las controversias que le son interpuestas, es una mala ley, o sea una ley ambigua y deficitaria en lo que a técnica legislativa se refiere. Ciertamente, no hay ley perfecta, por eso resulta imprescindible la existencia de cortes y tribunales constitucionales en las democracias modernas, pero una legislación que sobrecarga la participación de dichas instancias es por definición una mala legislación, pues cualquier fallo que se emita ante una controversia legal puede dar lugar a todo tipo de suspicacias que terminen vulnerando la credibilidad y legitimidad de la instancia judicial responsable. Inversamente, cuando la intervención de las cortes y tribunales es esporádica, lo más seguro es que la legislación correspondiente sea lo suficientemente clara y explícita como para inhibir confrontaciones entre posibles querellantes. ${ }^{3}$ A este punto volveré más adelante. Por ahora quisiera precisar el asunto de este estudio.

Para examinar la actuación del TEPJF en las elecciones de 2009 consideraré un total de cuatro casos jurídicos que recibieron impugnaciones por parte de los partidos políticos. Dichos casos tienen que ver, sobre todo, con la problemá-

${ }^{2}$ Cuestión que el TepjF simplemente omite a la hora de evaluar sus competencias y sentencias. Véase, por ejemplo, la opinión de la magistrada presidenta en: Alanis FiguerOA, M. C. "La elección federal de 2009: aspectos cuantitativos desde la justicia electoral federal", en Este País, México, No. 224, noviembre de 2009, pp. 14-17.

3 Sobre el asunto de la ambigüedad normativa en México véase Cansino, C. El desafío democrático. La transformación del Estado en el México postautoritario, Cepcom/Jus, México, 2004, en especial el capítulo 3: "La transformación del Estado: límites y perspectivas". 
tica del principio de neutralidad en relación con la propaganda de los partidos políticos en la difusión de programas de gobierno, principio estipulado por la legislación electoral para garantizar la equidad de las contiendas y desalentar formas veladas de presión o coacción del voto, que para efectos prácticos constituye el bien jurídico tutelado por la ley electoral. Para proceder con el análisis he optado por sacrificar el detalle, o sea lo particular, para concentrarme en los aspectos más generales, lo cual responde no sólo a una cuestión de espacio sino también a mis propias capacidades profesionales, pues al no ser abogado estoy en desventaja para profundizar en aspectos jurídicos muy especializados, propios de este tipo de resoluciones legales.

En ese sentido, me referiré, en lo general, a los cuatro casos propuestos para su análisis. Para ello, dividiré mis consideraciones en dos apartados: $a$ ) los fallos del TEPJF en estos casos con respecto a la legislación electoral vigente, o sea en las circunstancias reales de nuestra democracia electoral, y $b$ ) los fallos del TEPJF en estos mismos casos en una situación democrática ideal, y como tal inexistente en nuestro país, situación que sólo puede imaginarse a partir de ponderar otras experiencias en el mundo. Más específicamente, mientras que en el primer apartado pretendo evaluar la mayor o menor pertinencia, congruencia y validez con las que el TEPJF falló los casos en cuestión en apego a la legislación vigente, en el segundo mi interés es examinar, más que la actuación del TEPJF en cada caso, la mayor o menor pertinencia, congruencia y validez de la propia ley electoral, aspectos que en un momento dado vuelven incluso insustanciales o irrelevantes (si es que el análisis demuestra las muchas obsolescencias y contradicciones que presumo tiene la legislación electoral en nuestro país) los propios casos que hoy se ventilan en los tribunales de lo contencioso. En estricto sentido, conviene aclarar desde ahora que una revisión de cuatro casos de todos los que ha fallado el TEPJF en ocasión de las elecciones federales de 2009, en temas igualmente controversiales (como denigración, propaganda negativa, libertad de expresión, entre otros muchos), no nos faculta para hacer mayores extrapolaciones o generalizaciones válidas para el sistema electoral en su conjunto. Con todo, aunque por ahora sólo puedo postularlo, estoy convencido de que las conclusiones que de mi análisis de casos puedan desprenderse son igualmente válidas para otros casos si se examinaran con los mismos criterios sugeridos aquí.

Llegados a este punto, es momento de plantear una tesis general que orientará mi búsqueda: que los fallos del TEPJF en casos de controversia sean legalmente correctos, o sea imparciales y apegados a derecho, y hermenéuticamente adecuados, o sea basados en interpretaciones convincentes o persuasivas de la ley, no significa que la ley que los jueces buscan preservar en sus fallos y sentencias sea la más adecuada para apuntalar la democracia electoral en nuestro país o que 
incluso sea una ley inobjetablemente democrática. En ese sentido, cada vez que el Tribunal falla sobre asuntos controversiales, con base en una ley muy ambigua en sus contenidos e insuficientemente democrática en materia electoral, se corre el riesgo de crear jurisprudencia en aspectos incompatibles o contradictorios de origen con la democracia; es como edificar un nuevo piso normativo sobre uno ya de antemano mal cimentado, con el resultado lógico de desmoronarse estrepitosamente a la menor provocación, cargándose a la propia democracia.

Además, por si este hecho no bastara, prevalecen en México mecanismos muy partidizados y poco transparentes para la designación de las autoridades de los órganos electorales (tanto del Instituto Federal Electoral, IFE, como del TEPJF) que vician de origen su credibilidad y ponen en entredicho la presunta imparcialidad y objetividad de las decisiones que toman y los fallos que emiten. En esas condiciones -cuestión que en principio me propongo evitar en este trabajo-, un examen deliberadamente aséptico sobre la ley y los fallos que en su nombre emiten los jueces, o sea un estudio estrictamente juridicista o legalista, resulta insustancial e inocuo frente a los muchos desafíos que la construcción de una verdadera democracia electoral plantea para el país; proceder así sería tanto como reproducir un engaño, o sea dar por normales y plenamente democráticos los usos y prácticas electorales que nos hemos dado, siendo que la mayoría de ellos tiene poco de normal y mucho de patológico si se mide con los cánones comúnmente aceptados para cualquier democracia que se precie realmente de serlo. Entiendo que los juristas procedan de esa manera, convirtiendo al objeto de sus reflexiones - la ley- en un absoluto, el principio y el fin de sus elucubraciones, pero conviene no olvidar que en nombre de la ley, o mejor del imperio de la ley, también se pueden cometer graves excesos y atropellos. En virtud de ello, prefiero adoptar una mirada relativista y escéptica con respecto a la norma que es demasiado complaciente o ceremoniosa. ${ }^{4}$ Por ello, antes de proceder con el examen puntual de los fallos del TEPJF según los criterios definidos arriba, quisiera hacer una consideración general sobre la ley electoral vigente en México y sobre las reformas introducidas a la misma en 2007.

\section{Consideraciones generales sobre el marco legal del sistema electoral mexicano}

Era inevitable que las reformas constitucionales aprobadas en materia electoral por el Congreso de la Unión y publicadas en el Diario Oficial de la Federación

${ }^{4}$ Exhortación que por lo demás postuló de manera insuperable el filósofo alemán Jürgen Habermas en su célebre obra Facticidad y validez (Trotta, México, 1997), o sea que primero están los hechos y luego la norma, y no al revés. 
el 13 de noviembre de 2007, así como las reformas al COFIPE aprobadas a fines del mismo año, generaran grandes controversias y posiciones encontradas. La cuestión electoral ha sido desde hace muchos años el eje de la democratización del sistema político mexicano, y al igual que en reformas electorales pasadas, la de 2007 confrontó a distintas posiciones acerca de la profundidad y la velocidad de los cambios requeridos, la viabilidad y la pertinencia de las reformas, los resultados esperados y sus posibles efectos contraproducentes; en suma, sus límites y perspectivas.

En lo personal, he fijado públicamente en varios medios una posición crítica sobre las reformas electorales de 2007, no tanto por sus adiciones, cambios y derogaciones, sino por sus diversas omisiones, mismas que tarde o temprano deberán afrontarse en las instancias legislativas correspondientes tan pronto como los comicios muestren en la práctica que tales asuntos ahora pospuestos 0 relegados sí son importantes para apuntalar nuestra democracia electoral.

Más específicamente, considero que la principal debilidad de las reformas electorales aprobadas reside en su carácter excesivamente coyuntural. En efecto, tal y como están planteadas, las modificaciones introducidas parecen buscar ante todo los mecanismos legales para revertir e impedir en el futuro los errores y los excesos que se presentaron en ocasión de las elecciones federales de 2006 y que pusieron en riesgo la contienda y dañaron la imagen del IFE y del TEPJF en lo que a su credibilidad y eficacia se refiere. Así, por ejemplo, según consta en la exposición de motivos de la iniciativa de cambios constitucionales en materia electoral, los partidos detectaron los siguientes puntos débiles a partir de los comicios federales de 2006: un excesivo protagonismo de los medios de comunicación en los procesos electorales con el afán de influir en los resultados, en sintonía con sus intereses particulares; un uso excesivo de descalificaciones y denuestos entre partidos y candidatos fuera de las reglas elementales de la convivencia entre adversarios; un gasto excesivo de los partidos en la promoción de sus campañas en los medios de comunicación; una excesiva exposición mediática de actores políticos con recursos públicos en tiempos electorales y que pueden influir en los resultados; una intervención mediática no controlada de la iniciativa privada a favor o en contra de ciertos partidos o candidatos; un Consejo General del IFE cuya eventual inexperiencia puede poner en riesgo la credibilidad de los comicios. Adicionalmente, haciendo eco de una percepción dominante entre los ciudadanos, los partidos coincidieron en que los tiempos y los gastos de las campañas eran excesivos.

En correspondencia con este diagnóstico de coyuntura, las reformas electorales de 2007 buscaron frenar estos potenciales nudos de conflicto. Así, por ejemplo, se establecen facultades al IFE para evitar mediante sanciones estrictas 
que los medios y la iniciativa privada vuelvan a tener un papel demasiado activo durante las campañas; se impide que el presidente de la República, los gobernadores y los alcaldes hagan publicidad durante las campañas; se establece que el IFE administre los tiempos del Estado en los medios de comunicación para que los partidos y los candidatos difundan sus propuestas, al tiempo que se prohíbe la contratación de espacios fuera de los tiempos oficiales; se establece que la publicidad de los partidos no podrá contener expresiones que "denigren" a las instituciones y a los propios partidos o que calumnien a las personas; se reducen los gastos y los tiempos de campaña y precampaña; se establece un mecanismo de renovación escalonada de los miembros del Consejo General del IFE. Adicionalmente, en respuesta a los reclamos por una mayor transparencia de los partidos en el manejo de sus recursos, en la iniciativa de ley secundaria se reduce el financiamiento privado y se faculta al IFE para vigilar los recursos públicos que ejercerán los partidos, sin las restricciones impuestas por los secretos bancario, fiscal o fiduciario.

Como se puede observar, el sentido y la orientación de estas reformas están directamente conectados con la coyuntura, o mejor con la lectura que los propios partidos han hecho acerca del proceso electoral de 2006. En principio, proceder así es normal y lógico, pues toda reforma responde a una serie de circunstancias percibidas como negativas y susceptibles de corregirse. El problema está más bien en que la coyuntura no siempre es el mejor rasero (o cuando menos no el único) para introducir cambios normativos de largo aliento, cambios con una perspectiva de larga duración y que abonen de manera eficaz e inequívoca a la maduración y la consolidación de la democracia electoral sin necesidad de someter a examen periódico sus reglas cada vez que la realidad muestre cuán insuficientes son. Más aún, mirar con el prisma de la coyuntura implica muchas veces mirar exclusiva o primordialmente desde los agravios y los posibles resarcimientos particulares o de grupo, quedando en segundo término los intereses superiores y de largo plazo, que son los de la nación en toda su heterogeneidad y diversidad. Por esta vía, los remedios terminan siendo casi siempre tan coyunturales como el propio diagnóstico, o sea tentativos y provisionales. ${ }^{5}$

\footnotetext{
${ }^{5}$ Tal parece, en descargo del Legislativo, que los otros poderes del Estado mexicano también padecen del mismo mal; es decir, no son capaces de mirar más allá de la coyuntura y el corto plazo. El Legislativo, como vimos, aprobando leyes coyunturales y superficiales como la electoral, y todas las demás de los últimos años; el Ejecutivo, implementando politicas que buscan aliviar de manera pasajera los rezagos sociales, como el programa Oportunidades y todos los demás, y el Judicial, porque se mueve en los estrechos límites de lo que las leyes cortoplacistas le permiten. Pero este mal no tiene por qué ser endémico ni irreversible, pues cada instancia tiene en sus manos la posibilidad de romper de algún modo el círculo vicioso: el Legislativo, anteponiendo los intereses nacionales a los intereses inmediatistas de las distintas fracciones partidistas; el Ejecutivo, proponiendo y concertando un proyecto de nación para el futuro (a treinta años, por ejemplo) y que hasta ahora brilla por su ausencia, y el Judicial, generando jurisprudencia con una
} 
Pero el problema no son sólo las omisiones. Incidir en la realidad desde una lectura ensimismada por la coyuntura también puede llevar a ciertos despropósitos o errores de apreciación; es decir, a sobredimensionar algunos temas y descuidar otros, alentando soluciones drásticas o incluso contradictorias con ciertos preceptos o libertades que a juzgar por muchos no sería prudente acotar o restringir, lo cual constituye el caldo de cultivo idóneo para que los actores inconformes o directamente afectados interpongan recursos de amparo contra la ley o incluso controversias constitucionales. Por ejemplo, si se percibe que los medios de comunicación incidieron en demasía en el proceso electoral, por qué no entonces regular sus contenidos en futuras contiendas. El problema es que "regular" muy bien puede confundirse con "censurar" si antes no se define claramente lo que se pretende. Huelga decir que por esta vía los artífices de las reformas -señaladamente los partidos mayoritarios- se verán enfrentados invariablemente a un caudal de críticas por una presunta extralimitación en sus funciones y atribuciones con tal de mantener sus propios intereses. De hecho, no son pocas las voces que han hablado de "partidocracia" para referirse a la actuación de los partidos con esta reforma, entendiendo por ello una perversión de la democracia en la que no existen suficientes mecanismos formales para contrarrestar o limitar el poder de facto de los partidos mayoritarios. ${ }^{6}$ Otras voces, por su parte, han señalado que no existen aún los incentivos necesarios para que los partidos vean disminuir sus muchas prerrogativas por la vía de reformas legales que sólo los propios partidos están facultados para introducir. Finalmente, por sus omisiones y excesos, algunos más han afirmado que la reforma en cuestión es impopular o incluso que constituye una contrarreforma electoral; es decir, un retroceso en lugar de un avance. Lamentablemente, todas estas interpretaciones tienen algo de verdad. La reforma electoral presentó algunos avances, pero el peso de las omisiones y la existencia de algunos despropósitos en la misma terminaron restándole fuerza y aquiescencia.

En suma, es posible detectar dos tipos de problemas en las reformas electorales de 2007: las omisiones y ciertos despropósitos. En virtud de ello, esta reforma presenta hasta cierto punto una paradoja si se compara con reformas electorales precedentes. Mientras que en el pasado las reformas electorales fueron muy limitadas, graduales y hasta timoratas debido a la hegemonía que el partido

visión de futuro aun a costa de desafiar las soluciones normativas preferidas por los legisladores. Sobre el tema de la necesidad de avanzar en las actuales circunstancias del pais hacia un proyecto de nación y sobre las consecuencias de no hacerlo, véase Cansino, C. "¿Por qué México no saldrá bien librado de la crisis económica?", en Este País, México, No. 224, noviembre de 2009, pp. 18-30.

${ }^{6}$ Sobre el fenómeno de la partidocracia en México véase CAnsino, C. "De la dictadura perfecta a la democracia imperfecta. Lo normal y lo patológico en la transición mexicana", en Revista Altamirano, México, No. 36, julio de 2009, pp. 31-56. 
CÉSAR CANSINO

gobernante mantenía sobre los procesos legislativos (aunque la reforma de 1996 permitió avances insoslayables debido a la debilidad que para entonces ya acusaba el régimen priísta), la reforma de 2007 también resulta insuficiente y gradual pero por otras razones: una visión dominante muy coyuntural de los problemas y defectos de nuestro sistema electoral por parte de los partidos mayoritarios.

Ciertamente, no hay reforma perfecta y mucho menos una que deje satisfechos a todos. Sin embargo, cuando existen buenas condiciones para alcanzar acuerdos y plasmarlos en cambios de largo aliento más allá de las exigencias coyunturales, y no se procede en consecuencia, el resultado será aún más insatisfactorio y puede motivar varios cuestionamientos. Que en el caso de la reforma que nos atañe existían condiciones óptimas para aspirar a cambios más ambiciosos que los alcanzados, es indudable. Así, por ejemplo, las reformas electorales se daban por primera vez en el marco de una reforma del Estado de gran calado y cuya aprobación e instalación en el Congreso de la Unión a principios de 2007 marcó el fin de una etapa de desencuentros sistemáticos entre las fuerzas partidistas y el inicio de otra más prometedora de negociaciones constructivas. Por otra parte, la integración de dicha Comisión para la Reforma del Estado proveyó a los partidos de un marco simbólico que colocaba como fines superiores tanto la construcción de todo un nuevo andamiaje institucional y normativo encaminado a asegurar la consolidación de la democracia, como la edificación largamente pospuesta de un Estado de derecho verdaderamente democrático. Es precisamente en esta perspectiva de largo aliento que deben evaluarse los alcances de las reformas electorales.

El principal avance de las reformas constitucionales es, sin duda, la restricción de la publicidad pagada para promover las campañas de partidos y candidatos. En efecto, nada justificaba la fuga extraordinaria de recursos públicos hacia los consorcios mediáticos con fines de proyección política. Para eso existen los tiempos oficiales del Estado, que concesiona las frecuencias a los medios privados. Sin duda, con esta decisión nuestro país adopta un principio básico de sana distancia entre los partidos y los medios que opera en prácticamente todas las democracias consolidadas del mundo. Sin embargo, su operacionalización en la ley secundaria no estuvo ajena de ciertas inconsistencias en lo que respecta a las facultades del IFE para administrar los tiempos del Estado destinados a los partidos en campaña y para sancionar a aquellos medios que incumplan con estas disposiciones.

De la mano con este asunto están varios más de igual importancia: el establecimiento de restricciones para que nadie sin excepción (ni la iniciativa privada ni funcionarios en activo, como el presidente de la República, los gobernadores y los alcaldes) pueda hacer publicidad durante los tiempos de campaña y por esta 
vía influya en los resultados; la regulación de los contenidos de la publicidad partidista para que ésta no denigre a las instituciones y a los propios partidos o calumnie a las personas; el establecimiento de lineamientos oficiales a los que deberán ceñirse los noticieros durante las campañas electorales. Indudablemente, pese a que estos aspectos buscan atender un problema coyuntural que hizo mella en las elecciones federales de 2006, resultan muy difíciles de reglamentar sin herir susceptibilidades. Las fronteras entre la regulación de prácticas y conductas y la censura suelen ser muy sutiles y siempre motivarán controversias. Por lo pronto, las reformas al COFIPE no ofrecieron las mejores alternativas para reglamentar el asunto sin vulnerar el principio de la libertad de expresión.

Así, por ejemplo, reglamentar los contenidos de las campañas no puede hacerse sin imponer unos criterios muy subjetivos y endebles: ¿quién puede establecer, por ejemplo, cuándo algo es "denigrante" o no lo es? Además, de acuerdo con la experiencia de muchas democracias consolidadas en el mundo, la negatividad de las campañas no es algo condenable per se. Según este criterio, corresponde sólo a los ciudadanos premiar o castigar a los candidatos por sus exabruptos 0 su discreción. Implícito, pues, en toda tentativa de regular los contenidos de las campañas para que se desarrollen según normas de respeto y prudencia, suele esconderse una concepción que subestima a los ciudadanos en sus capacidades de discernir por sí mismos sus preferencias, una concepción paternalista de la política que concibe a los ciudadanos como menores de edad. Asimismo, en caso de difamación y calumnias, ya existen los instrumentos legales para que los afectados interpongan una demanda y puedan resarcir el daño moral, aunque también en este terreno existen muchas inconsistencias jurídicas.

Algo similar puede decirse de la restricción a particulares para que empleen a los medios en tiempos de campaña para difundir sus ideas, por más que se pretenda con la medida preservar la contienda de factores que la contaminen. En efecto, no puede reglamentarse en este ámbito sin afectar el principio de la libertad de expresión. Pero quizá el asunto más polémico está en imponer lineamientos a los medios, y en particular a los noticieros, durante los tiempos electorales, bajo la amenaza de retirar temporalmente del aire a los medios que incumplan dichas disposiciones. Como era de esperarse, el asunto ha despertado un intenso debate. En lo personal, me he pronunciado por la defensa irrestricta de la libertad de expresión. Más aún, después de décadas de imposiciones y controles oficiales sobre los medios, considero un avance que los medios o los noticieros fijen abiertamente sus posiciones con respecto a los candidatos. Con ello nos ahorramos las simulaciones del pasado, donde muchos medios aparentaban ser plurales y equitativos, pero en el fondo promovían veladamente sus propias preferencias. De nuevo, en este asunto toca exclusivamente a los ciudadanos 
premiar o castigar a los medios por su imparcialidad o parcialidad, en este caso con el favor o no de su audiencia o fidelidad.

Con estas consideraciones se puede ejemplificar uno de los riesgos de reformar una ley a partir de ponderar exclusivamente cuestiones coyunturales. Por esta vía es común que se sobredimensionen algunos aspectos en detrimento de otros. El resultado puede ser acortar ciertas libertades en aras de solucionar un problema específico. Quizá la medicina puede ser eficaz, pero si causa daños colaterales graves no hay más remedio que cambiarla. Precisamente por ello, al prosperar ahora este tipo de soluciones, no pasará mucho tiempo para que se deroguen. Ninguna democracia puede levantarse si no es en el piso firme de los derechos y las libertades individuales.

Pero siguiendo con los avances de las reformas electorales de 2007, se introduce un aspecto de la mayor importancia: la disposición para que el IFE vigile los recursos públicos que ejercerán los partidos sin las restricciones que imponen los secretos bancario, fiduciario o fiscal. Para ello se propone constituir en el IFE una Unidad de Fiscalización de los Recursos Públicos de los Partidos Políticos. Sin duda, este punto atiende un reclamo por transparentar las actividades y el manejo de recursos de los partidos, y por ello es relevante. Sin embargo, existían en el tintero muchas otras propuestas en este sentido, que al final no se concretaron. Así, por ejemplo, no resultaba desdeñable la propuesta de incluir a los partidos entre las instancias públicas sujetas a la Ley de Transparencia y Acceso a la Información. Como quiera que sea, hay aquí un avance, pero su pertinencia tiene que ver también con la existencia de sanciones graves para los partidos que incumplan con la obligación que se estipula en la reforma.

Finalmente, las reformas electorales de 2007 representan un avance en lo que a la reducción de tiempos de campañas y precampañas se refiere. Sin duda, este asunto, junto con la restricción de contratar publicidad pagada y la reducción del financiamiento privado de los partidos, reduce sensiblemente los hasta ahora excesivos gastos de nuestra democracia electoral. Sin embargo, comparada con varias democracias consolidadas, los tiempos de las campañas estipuladas por las reformas siguen siendo demasiado largos. He aquí otro punto que tarde o temprano deberá ajustarse.

Hasta aquí los principales avances de la reforma electoral de 2007. Como vimos, pese a sus aportes, ninguno está libre de problemas y queda la sensación de que se podía llegar más lejos sin necesidad de afectar aspectos colaterales como la libertad de expresión. Si evaluamos las reformas por su pertinencia para evitar o solucionar problemas coyunturales, es decir los problemas que se presentaron en ocasión de las elecciones federales de 2006, el resultado es positivo, aunque podía llegarse más lejos. Sin embargo, proceder así no es suficiente. Más 
que la coyuntura, el verdadero criterio para establecer los alcances de la reforma electoral es su contribución para consolidar la democracia en el futuro mediante el firme establecimiento de prácticas e instituciones electorales confiables y eficaces, en una perspectiva integral. Lamentablemente, desde esta perspectiva, la reforma electoral resulta insuficiente. Si en el pasado del viejo régimen se impuso una suerte de gradualismo a la hora de aprobar las reformas electorales, más por las circunstancias todavía favorables al partido hegemónico, en la reforma de 2007 el gradualismo también terminó imponiéndose, aunque por otras razones. A la larga, a la hora de los balances, con esta reforma los partidos nos siguen debiendo. Con esta reforma se volvió a perder la posibilidad de ir al fondo de muchos de los problemas de nuestro sistema electoral.

Son tantos los temas que se quedaron fuera de esta reforma que no hay más remedio que calificarla de tentativa y provisional. Considérense si no los siguientes:

1) El asunto de las candidaturas independientes quedó en el limbo, pues se omite el párrafo que las impedía, pero no se reglamenta nada al respecto.

2) El tema de la reelección de diputados y senadores simplemente no fue considerado.

3) Nada tampoco se avanzó sobre el voto de los mexicanos en el extranjero, que requiere de un régimen especial para darle cauce.

4) El mecanismo de selección de los consejeros del IFE continuó siendo una competencia exclusiva de los partidos con representación en el Congreso, no obstante que este hecho vicia de origen la credibilidad del árbitro por más que se establezcan mecanismos más abiertos y transparentes para su designación.

5) No se incluye nada sobre la democracia interna de los partidos, aunque es un tema polémico y no existe consenso a nivel mundial sobre la pertinencia o no de establecer mecanismos al respecto.

6) No se incluye nada sobre referéndum, plebiscito, iniciativa legislativa popular y revocación de mandato, que son figuras fundamentales en las democracias modernas.

7) Nada hay en la legislación acerca de reducir el número de legisladores y de redefinir la fórmula mixta de diputados y senadores de mayoría simple y de representación proporcional, que genera sobrerrepresentación y que ha sido descartada por la mayoría de las democracias modernas en aras de una mejor representatividad política.

8) No se introdujo nada sobre segunda vuelta y mecanismos alternativos para evitar conflictos en elecciones muy competidas y con resultados muy cerra- 
CÉSAR CANSINO

dos; el asunto de la equidad de género en las candidaturas de legisladores parece tener todavía algunos reparos.

9) Se descuidó la cuestión de nuevas tecnologías tanto para las campañas como para blindar el programa de resultados preliminares, o bien introducir la urna electrónica.

10) No se quiso ir más lejos en la centralización de las elecciones mediante la creación de un Instituto Nacional de Elecciones que concentre la facultad de organizar todos los comicios del país, con lo cual se frenarían las irregularidades y dispendios que suelen presentarse en los institutos electorales estatales, muchas veces sometidos a los poderes fácticos y cacicazgos locales (la ley sólo establece la posibilidad de que el IFE organice comicios estatales a petición de los propios poderes formales de cada entidad).

11) Tampoco se quiso unificar los tiempos electorales para todo el país, lo cual representaría un enorme ahorro de recursos y esfuerzos, y como éstos, hay muchos asuntos pendientes más.

Pero además de las omisiones, se introdujeron en la Constitución y en la ley secundaria algunos puntos muy polémicos que bien podrían ser calificados de retrocesos. Tal es el caso de la creación de la figura de un contralor del IFE designado por los partidos en el Congreso, quien tendría las tareas de vigilar la actuación de los consejeros electorales y sugerir su remoción a criterio del mismo. Es un retroceso porque vulnera la autonomía que debe prevalecer en el Instituto y permite a los partidos interferir en los asuntos internos del mismo. Algo similar puede decirse de la intención de impedir las coaliciones, o bien que en el caso de candidaturas comunes, a cada partido se le abonen sus propios votos para establecer si conserva o no el registro. Obviamente el tema inquieta sobre todo a los llamados partidos pequeños, pero no en aras de restarles fuerza puede sacrificarse lo que en sí mismo es una conquista: la posibilidad de establecer alianzas y coaliciones electorales. Tarde o temprano, la ley deberá buscar una fórmula distinta para atender prudentemente este punto.

20

\section{Los fallos del TEPJF en el marco de la democracia electoral realmente existente}

El TEPJF recibió durante el proceso electoral federal de 2009 varios recursos cuyos fallos sientan un precedente en diversos aspectos de la materia electoral. En particular examinaré aquí las sentencias de cuatro casos que tienen que ver con 
el principio de neutralidad aplicado a la propaganda de los partidos políticos. ${ }^{7}$ Más específicamente, se me ha solicitado reflexionar, a partir de estos casos, en qué medida un partido político puede utilizar en sus campañas políticas los contenidos de los programas oficiales de manera lícita, así como realizar gastos de campaña en materia de salud, que son parte de programas oficiales, para buscar la afiliación partidista y un mejor posicionamiento durante las campañas electorales. La pregunta aquí es: ¿si este tipo de propaganda o gastos vulnera o no la prohibición del poder público y de los partidos de intervenir ilegalmente en una elección, por afectar la libertad del sufragio o la equidad de la contienda?

En el primer caso - una querella en contra del pan por difundir, antes de comenzar las campañas electorales, una propaganda institucional aprovechándose de supuestos logros del gobierno federal-, el TEPJF falló que el asunto era improcedente, y determinó que todos los partidos tienen la libertad de usar en su propaganda política los programas oficiales como parte de sus facultades para expresarse libremente en el debate público a fin de que el electorado decida con mayor información, a excepción de todo mensaje que pretenda inducir, coaccionar o presionar en forma indebida el voto. Sin embargo, la resolución no fue unánime, pues se aprobó con el disenso de dos magistrados, cuyos argumentos abonan a la discusión sobre la pertinencia o no de la sentencia final.

En el segundo caso - una querella en contra del PAN por difundir en su sitio web un folleto publicitario sobre diferentes acciones de gobierno, y donde se externó la frase: "si pierde el gobierno, perdemos los mexicanos"-, el TEPJF falló que la queja era procedente, por lo que determinó que dicha propaganda y la frase contenida en ella eran ilegales por inducir en forma indebida a los electores a votar a favor del PAN. Pero al igual que en el primer caso, dos magistrados expresaron su disenso y se manifestaron a favor del debate libre.

En el tercer caso - una querella en contra del pan por difundir promocionales en los que se difundían diferentes acciones del gobierno federal, mismas que aparecían como logros del presidente y del PAN-, el TEPJF falló que la queja era improcedente y determinó por mayoría de los magistrados, a excepción de uno que presentó varias objeciones, que el uso de la figura presidencial en la propaganda partidista no es constitutiva de presión o coacción a los electores.

En el cuarto caso - una querella en contra del Partido Nueva Alianza por utilizar recursos públicos para realizar mamografías gratuitas para la detección del cáncer en las mujeres, con la finalidad de posicionar a dicho partido y lograr un mayor número de afiliados en tiempos electorales-, el TEPJF falló que la queja

\footnotetext{
7 Para efectos de identificación, los casos en cuestión, de acuerdo con la clasificación del TEPJF, son: suP-RAP-15/2009, SUP-RAP-103/209, SUP-RAP-156/2009 Y SUP-RAP-250/2009.
} 
era procedente y determinó que los partidos no pueden hacer gastos para fines sociales en materia de salud que tengan por objeto afiliar a ciudadanos durante un proceso electoral.

Lo primero que salta a la vista en todos estos fallos legales es que exigieron por parte de los jueces un ejercicio ineludible de interpretación de la legislación vigente, ejercicio por necesidad subjetivo y controversial, producto de la ambigüedad de la propia ley. Prueba de ello es que en ningún caso las resoluciones se alcanzaron por unanimidad, y que muchos de los argumentos externados por los magistrados que disentían de las posiciones mayoritarias eran totalmente opuestos a los que terminaron imponiéndose. En virtud de ello, no sólo se ponen de manifiesto las deficiencias de la ley, en la medida en que admite interpretaciones contrastantes, sino que justifica plenamente la necesidad de evaluar lo más objetivamente posible la actuación del TEPJF.

En segundo lugar, no se puede establecer que el TEPJF haya actuado en cada uno de estos casos movido por criterios extralegales (preferencias partidistas, inclinaciones ideológicas, revanchas políticas, etcétera), pues la legislación faculta a los jueces a interpretar la ley conforme a los criterios que cada uno tenga a bien ponderar, pero eso no significa que las sentencias finales hayan sido las más correctas o adecuadas, no desde un criterio estrictamente legal sino, sobre todo, funcional con los principios propios de una democracia. Así, por ejemplo, siguiendo la máxima según la cual lo que la ley no prohíbe entonces es permitido, es válida la sentencia del TEPJF que determina como lícito que los partidos utilicen en su propaganda política los programas oficiales (caso 1). En mi opinión, ello es correcto, sobre todo si se privilegia el criterio de la libertad de expresión por sobre otros que quizá preocupan más a ciertos actores políticos, como la equidad en las campañas. Lo que sorprende en este caso es que sean, paradójicamente, los propios partidos políticos -o algunos de ellos- los que pretendan, al interponer quejas ante el TEPJF, restringir sus propias facultades para expresarse libremente. Algo similar puede decirse del segundo caso, con la salvedad que determinar si una frase propagandística es ilegal por inducir en forma indebida el voto, siempre será algo muy subjetivo y, en consecuencia, parcial. En ese sentido, más que las implicaciones y la supuesta intencionalidad de ciertas expresiones, lo que debe someterse a juicio es la propia ley. Aquí, la pregunta no es si una determinada expresión o frase de campaña es legal o ilegal, sino qué sentido tiene mantener una ley que restringe la libre expresión de los partidos con base en criterios de juicio que siempre serán subjetivos y arbitrarios. En el tercer caso, por su parte, el fallo del TEPJF fue el más sensato, pues determinar en cuáles situaciones el empleo de la figura presidencial en la propaganda partidista es ilegal por coaccionar el voto y en cuáles no, podía 
conducir a alegatos estériles e interminables, con las mismas consecuencias que en el caso 2, o sea abrir la puerta a la subjetividad y arbitrariedad. En el cuarto caso, por último, el fallo fue el más congruente con el principio de neutralidad establecido en la ley, que obliga a los actores políticos a señalar explícitamente en la promoción de sus obras publicas que: "este programa es público y queda prohibido su uso para fines distintos del desarrollo social". Pero desde un punto de vista más pragmático, para un país con tantas carencias y rezagos, que un partido prefiera usar los recursos a su disposición para hacer obra social directa en lugar de derrocharlos en pura propaganda tiene algo de meritorio, por lo que no puede invalidarse en automático.

En tercero y último lugar, con los elementos referidos hasta aquí, creo estar en condiciones de ofrecer una primera respuesta a la interrogante planteada por el TEPJF: ¿la propaganda de programas gubernamentales o los gastos en obras sociales durante la campaña por parte de los partidos políticos vulneran o no la prohibición del poder público y de los partidos de intervenir ilegalmente en una elección, por afectar la libertad del sufragio o la equidad de la contienda? De entrada, considero que la pregunta da por sentada una cuestión que en sí misma es cuestionable: la prohibición del poder público y de los partidos de intervenir ilegalmente en una elección. En lo personal, aunque entiendo las razones históricas que la justifican, creo que es un exceso prohibir al poder público intervenir en la contienda y limitar la libre expresión de los partidos (ya sea en el uso propagandístico de los programas gubernamentales o de la figura presidencial, o restringiendo sus dichos y frases por considerarlos coaccionadores del voto), sobre todo si se pondera como criterio discriminador (bien jurídico tutelado) el derecho a la libre expresión, y si se considera igualmente, como veremos después, que el juez último de una contienda electoral es el ciudadano con su voto. Más aún, que un presidente intervenga en los procesos electorales no significa necesariamente que ello será redituable para su partido en campaña, sino que puede tener el efecto contrario, en función de la mayor o menor popularidad del mandatario. De igual modo, el uso propagandístico de los programas gubernamentales o de la figura presidencial tampoco garantiza el éxito electoral al partido en cuestión, pues depende de la percepción social que se tenga del desempeño del gobierno. $Y$ finalmente, el recurso a frases alarmistas o subliminales en las campañas no asegura que tendrán el efecto esperado, sino que muchas veces pueden resultar contraproducentes en la captación de votos. Por todo ello, sostener a priori que la intervención del presidente en las contiendas, o el uso propagandístico de programas oficiales o de la figura presidencial, o el recurso a expresiones supuestamente manipuladoras son prácticas que violentan la legalidad, es algo muy relativo, amén de que limitarlas legalmente tampoco 
asegura la equidad de la contienda ni la libertad del sufragio ni la neutralidad que se pretende por parte de los actores políticos (cuestión esta última que por lo demás resulta contradictoria con la condición, por definición parcial, de los partidos y los gobernantes), las cuales dependen de muchos otros factores, ciertamente más relevantes que aquéllos, y que permanecen todavía en un estado primario en la legislación vigente, tales como los mecanismos de designación de los órganos electorales, el financiamiento de los partidos, la reelección de legisladores, etcétera.

En síntesis, el TEPJF actuó en todos estos casos con apego a derecho, buscando las soluciones más saludables de acuerdo a sus atribuciones específicas y a las disposiciones legales a su alcance. Pero esto no significa, por razones que puntualizaré en el siguiente apartado, que las resoluciones sean las más congruentes con las exigencias de una democracia moderna. De entrada, adelanto, creo que debe cuestionarse seriamente si el empleo de propaganda oficial por parte de los partidos, o el recurso a frases de campaña presumiblemente coaccionadoras del voto, o el uso de la figura presidencial en los procesos electorales, o el gasto social partidista en tiempos de campaña electoral, son situaciones que, como se presume, realmente hacen inequitativa una contienda, o cancelan la libertad del sufragio o violentan la neutralidad del poder público y de los partidos, principios rectores de una elección libre. En lo personal, puedo entender que haya razones históricas que expliquen que nuestra normatividad electoral sea particularmente sensible a regular estas cuestiones, como las inequidades de los comicios, las simulaciones electorales o la centralidad del presidente durante la era del partido único, pero transferir ad infinitum esta sensibilidad en la legislación electoral no puede hacerse sin menoscabo del pleno reconocimiento de las facultades de discernir y elegir de los propios ciudadanos, a quienes las autoridades y las leyes se empeñan en preservar de posibles "contaminaciones" que afecten su buen juicio a la hora de emitir su voto, o sea de mantenerlos en un estado permanente de minoría de edad. He ahí el problema estructural inherente a todos estos fallos legales. De hecho, estar enfrascados todavía en discusiones de este tipo no hace sino evidenciar lo lejos que estamos de materializar una democracia electoral madura. Desde este rasero imaginario, pierde todo sustento discutir la pertinencia o no de usar propaganda oficial o la corrección o no del lenguaje empleado por los partidos para comunicar su mensaje, cuestiones todas irrelevantes desde el momento en que se reconoce que el ciudadano es lo suficientemente maduro para tomar libremente sus decisiones por más que los actores busquen a toda costa persuadirlo por distintos medios. Más aún, en una democracia de este tipo toca exclusivamente a los ciudadanos, más que a un tribunal electoral, premiar o castigar con su voto los excesos retóricos y malos manejos de sus partidos y 
candidatos. Son, en última instancia, los ciudadanos los que, de acuerdo con su escala de valores, establecerán si un candidato abusa del uso de propaganda oficial, o si un partido es muy burdo al usar la figura presidencial, o si emplea una retórica tendenciosa, y si son todas ellas prácticas o conductas que deban castigarse en las urnas, lo cual vuelve insustancial que se legisle al respecto, al menos no con la obsesión con que se ha hecho en nuestro país. Obviamente, esto no significa que no deba haber una legislación electoral precisa y expedita, pero en todo caso se trataría de una normatividad muy general en sus contenidos, fundada más en la confianza que en la desconfianza, empezando por el reconocimiento pleno de la madurez de los electores, cuestión todavía ausente en la nuestra.

\section{Los fallos del TEPJF en el marco de una situación democrática ideal}

Si algo sugiere la argumentación anterior es que evaluar los fallos del TEPJF en función de la propia legislación vigente es un ejercicio insuficiente y sesgado para determinar si con esos fallos se preservan o se vulneran principios presumiblemente fundamentales para la democracia, tales como la neutralidad de los partidos, la libertad de expresión, la libertad del sufragio o la equidad de la contienda. Por esa vía sólo estaríamos convalidando (legitimando) implícitamente (aun sin proponérnoslo) una normativa -en este caso la electoral- que resulta, tal y como está diseñada, muy limitada o incongruente respecto a esos principios o valores democráticos que se pretenden preservar; o que se quedó atrapada en concepciones obsoletas, en la medida en que se fue modificando periódicamente para contrarrestar usos y costumbres antidemocráticos muy acendrados en la cultura política y el imaginario colectivo (fraudes, manipulaciones, inducción y compra del voto, simulaciones, imposiciones, "concertacesiones”, caídas del sistema, etcétera), y que hoy, en lugar de permitir un salto a niveles superiores de democraticidad, nos condenan a la mediocridad y el estancamiento. En ese sentido, en materia de legislación electoral, quizá llegó la hora de mirar más al futuro que al pasado, de ponderar más los máximos posibles en lugar de los mínimos deseables, o sea de sacudirnos los prejuicios de un pasado ciertamente ominoso pero que al sobredimensionarlo en el presente nos impide avanzar. De ser así, lo que cojea es la ley, por lo que los fallos que en su nombre realicen las autoridades judiciarias respectivas terminan siendo insustanciales, circulares, baladíes. 
CÉSAR CANSINO

En virtud de ello, un ejercicio más fecundo sería evaluar la sustancia última de los fallos del TEPJF, o sea los principios democráticos que intenta salvaguardar, no en función de una ley específica que no convence a nadie sino de una situación ideal de la democracia, deducida de múltiples experiencias nacionales más democráticas que la nuestra. Por esta vía no sólo tendríamos más elementos para examinar las sentencias del TEPJF, sino para evaluar la propia ley electoral y la democracia que tenemos. Para el efecto, consideraré los cuatro principios que he venido desarrollando hasta ahora: neutralidad de los partidos, libertad de expresión, libertad del sufragio y equidad de la contienda.

\section{A) Neutralidad de los partidos}

En principio, resulta incongruente exigir neutralidad a algo o alguien que por definición no puede ser neutral, como un partido político o un militante partidista. Como su nombre lo indica, un partido es una parte de algo, y se distingue de las demás partes por las causas e ideales que dice defender y promover en el seno de la sociedad en la que interactúa. De ahí que aspirar a la neutralidad partidista en una contienda electoral sólo puede plantearse desde la ingenuidad

o el prejuicio histórico (en los términos esbozados arriba). En ese sentido, que un partido político pretenda ganar electores explotando a su favor los éxitos de los programas gubernamentales o la figura del presidente, empleando expresiones intimidantes o subliminales, o realizando programas sociales, es una cuestión secundaria o accesoria en las democracias maduras, y por lo tanto mantiene en esas realidades escasa o nula atención en la normatividad electoral. Más específicamente, suelen priorizarse otros aspectos en referencia a los cuales la pretensión de neutralidad partidista pierde sentido y se desdibuja por completo. En primer lugar está la libertad de expresión, valor supremo de todo ordenamiento democrático liberal, y que como tal se extiende por igual a todos los individuos $\mathrm{u}$ organizaciones colectivas, incluyendo los partidos políticos. Si acaso, lo que la ley prescribe para los partidos en tiempos de campaña son los espacios, tiempos y recursos destinados para hacer proselitismo, pero nunca los contenidos y el lenguaje de su proselitismo, o sea de su propaganda política (ya sea que se refieran a programas oficiales o a éxitos gubernamentales o que empleen expresiones ofensivas o intimidantes). En ese sentido, censurar a un partido o a un candidato por considerar que ofende ciertos principios no sólo significaría una violación a la libertad de expresión sino que obligaría a erigir tribunales inquisitoriales (por definición, subjetivos y parciales), supuestos guardianes de las buenas costumbres y modales, una figura no sólo arcaica sino incompatible 
con los valores de la democracia. En todo caso, si alguien se siente difamado o injuriado por la propaganda electoral de un partido o un candidato siempre tendrá a su alcance el recurso de demandarlo y de exigir la reparación del presunto daño moral en apego a las leyes existentes en materia de justicia civil y penal, igual y como ocurre normalmente entre personas físicas y morales. En segundo lugar está la propia vocación democrática de los ciudadanos, quienes eligen libre y responsablemente a sus candidatos de acuerdo con sus preferencias y valores, lo que equivale a decir que son los ciudadanos en su calidad de electores los verdaderos jueces de una contienda. A ellos y sólo a ellos les toca premiar o castigar a aquellos candidatos o partidos con los que se identifican o que de plano alucinan e, indirectamente, las formas y mensajes que emplearon para intentar posicionarse (descalificaciones de sus adversarios, campañas negativas, diplomacia, insultos, congruencia, claridad, corrección política, demagogia, contundencia, honestidad, etcétera) según los criterios y valores que cada quien profese. No es necesario decir que nuestra realidad nacional se encuentra a años luz de una situación como la descrita. En lugar de hacer valer la libertad de expresión hasta sus últimas consecuencias, nuestra legislación mantiene formas disfrazadas de censura que abren la puerta a todo tipo de suspicacias y resquemores. En lugar de confiar plenamente a los ciudadanos la decisión de elegir responsable y maduramente a sus representantes, las autoridades y las leyes los siguen concibiendo como ignorantes o menores de edad en asuntos políticos, por lo que hay que precaverlos de la maledicencia y guiarlos por el buen camino, o sea, se sigue desconfiando de ellos. Y por si esto no bastara, nuestro sistema de procuración de justicia está en pañales en lo que a derecho de réplica y resarcimiento de daño moral por difamación y calumnia se refiere.

\section{B) Libertad de expresión}

Ya he comentado a lo largo de este ensayo la importancia que tiene para cualquier sistema electoral preservar y fomentar la libertad de expresión, valor supremo de la democracia, y lo lejos que estamos en México de hacer valer este precepto, sobre todo después de las reformas electorales de 2007. Sólo añadiría en esta parte que en las democracias modernas dejaron de discutirse hace mucho cuestiones como las que todavía se discuten en la nuestra. En aquéllas, por ejemplo, nadie se ocupa ni preocupa de si los partidos y candidatos deben o no articular sus campañas electorales observando ciertos preceptos y disposiciones legales aun a costa de constreñir el debate libre de las ideas. Este tipo de consideraciones simplemente no tiene lugar desde el momento que se da por sentada 
la primacía del valor de la libertad de expresión por sobre cualquier otro criterio. En ese sentido, lo que podría motivar cuestionamientos por parte de los actores políticos en campaña no es el hecho de ser aludidos de manera negativa por sus adversarios, dada la enorme permisividad de la libertad de expresión de la que gozan, sino sentirse en un momento dado limitados o condicionados en su capacidad para expresarse libremente. Ese sí que sería un escándalo que podría vulnerar sensiblemente la legitimidad de una democracia consolidada. Además, se presume en estas realidades que los actores políticos desarrollarán patrones de conducta responsables que los llevarán a autolimitarse a la hora de referirse a sus contrincantes o de enviar mensajes incendiarios que en lugar de concitar apoyos puedan generar el efecto contrario, pero aun en esa eventualidad, es responsabilidad de los propios políticos profesionales exhibir prudencia o soberbia, y en ningún caso la normativa electoral los coartará o disuadirá para no hacerlo.

Asimismo, cuando en tiempos electorales un candidato denuesta a otro con fundamentos (o sea, lo exhibe públicamente como un político corrupto o deshonesto), lo más probable es que el candidato denostado renunciará a sus pretensiones electorales, bajo el entendido de que el ofendido, más que él, es la ciudadanía a la que pretendía engañar con una imagen ficticia. Salta a la vista que la democracia en México camina por el sentido contrario: en lugar de apuntalar la libertad de expresión, los partidos promueven leyes y juicios para frenar el libre debate de las ideas por considerar que pueden resultar raspados innecesariamente por sus contrincantes más poderosos, o que éstos, sobre todo los partidos gobernantes, se pueden aprovechar de su posición más ventajosa políticamente hablando para utilizar a su favor los éxitos de programas gubernamentales o la infraestructura del poder. Huelga decir que se trata de percepciones estériles que en lugar de apuntalar la democracia la pervierten de origen. Y si esto pasa en el ámbito electoral, donde la libertad de expresión es casi una condición sine qua non, lo más seguro es que ese derecho estará igualmente castigado en otros ámbitos de la vida pública, como en las tentativas recientes por penalizar el aborto o en la supresión de libertades y garantías ciudadanas en nombre del combate al crimen organizado. En otras palabras, cuando la libertad de expresión comienza a "reglamentarse" en lo electoral es un síntoma inequívoco de que está por sobrevenir una enfermedad más grave, propia de los tiempos de cinismo que atravesamos, tiempos en los que un político exhibido en sus fechorías no sólo no renuncia sino que se victimiza, y en ocasiones hasta capitaliza a su favor las denuncias en su contra, aprovechando las inconsistencias legales. Por lo demás, como se verá en los siguientes incisos, no es por la vía de la reglamentación de la libertad de expresión como se garantizan en la práctica cuestiones como la libertad del sufragio o la equidad de la contienda. 


\section{c) Libertad del sufragio}

Para este asunto retomo el caso en donde el TEPJF resolvió sancionar al PAN por difundir la frase: "si pierde el gobierno, perdemos los mexicanos". Según la sentencia respectiva, se determinó que dicha frase era ilegal por inducir en forma indebida a los electores a votar a favor del PAN, es decir, por afectar la libertad del sufragio. Obviamente, una sentencia tan absurda como ésta sólo puede prosperar en el marco de una legislación electoral igualmente absurda en muchos de sus preceptos, y sería impensable en una democracia más evolucionada. De entrada, resulta un despropósito establecer una relación causal entre una frase de campaña, cualquiera que ésta sea, y su impacto para inducir el voto, y en esa medida interferir en la libertad del sufragio. De nuevo, esa manía por dotar a un cuerpo colegiado -en este caso al TEPJF- de una capacidad o atribución para determinar cuestiones que nadie puede determinar sin recurrir a valoraciones subjetivas y arbitrarias. Si calificar la intencionalidad implícita de un lema de campaña resulta una tarea tendenciosa y sesgada, determinar si esa expresión sustrae a los electores la libertad para sufragar, raya en lo ridículo. Por esta vía llegamos a una paradoja: al facultar legalmente a un tribunal para determinar si un lema de campaña es ilegal porque induce el voto y coarta la libertad del sufragio, dicho tribunal es el que de facto termina sustrayendo a los ciudadanos su capacidad para elegir libremente, bajo el supuesto de que una tarea como ésta requiere tribunales calificados para decidir en nombre de una ciudadanía incapaz de hacerlo por sí misma. Por lo demás, son factores de otra índole los que en realidad ponen en peligro la libertad del sufragio, y no el empleo tendencioso de ciertos lemas de campaña que según esto pueden tener un enorme poder de disuasión, igual de explosivo que una bomba molotov. Así, la partidocracia, que al otorgar una gran centralidad a los partidos en las decisiones públicas que afectan a la sociedad, usurpan un primado que en realidad le corresponde a la ciudadanía.

En otras palabras, ahí donde los partidos mayoritarios concentran la iniciativa de la acción pública de acuerdo con sus intereses y ambiciones, los ciudadanos quedan supeditados a los caprichos de aquéllos. Así, por ejemplo, en el caso de nuestro país, corresponde a los propios partidos determinar quiénes pueden contender y quiénes no en las elecciones (de entrada, un candidato independiente queda excluido de esta posibilidad), quiénes van a calificar la elección y quiénes van a convalidarla (por la vía de la designación de los consejeros del IFE y los magistrados del TEPJF), e incluso quiénes podrán votar y quiénes no (así, los mexicanos en el extranjero, a quienes no se les han extendido plenamente los 
derechos políticos de los residentes locales). Éstas sí son formas reales de limitar el sufragio y no nimiedades, como una frase o un lema de campaña.

\section{D) Equidad de la contienda}

De manera similar al punto anterior, sostener que la equidad de una contienda electoral se puede vulnerar por el empleo sesgado de propaganda oficial por parte de un candidato o partido, o que una excesiva intervención proselitista de un gobernante a favor de su partido en campaña hace inequitativa una elección, o que el uso propagandístico de la figura presidencial por parte del partido gobernante es una práctica desigual, son cuestiones irrelevantes en el marco de una democracia consolidada, por las mismas razones que los casos anteriores: el reconocimiento de la madurez de los electores para discernir entre las distintas ofertas, la imposibilidad de establecer a priori una relación directamente proporcional entre propaganda oficial y captación de votos, etcétera. Además, en el caso de nuestro país existen factores estructurales que realmente amenazan de origen la equidad de las contiendas y que por fuerza de la costumbre ya nadie discute; son cuestiones tan importantes que hacen palidecer por inocuas y frívolas a todas las que son regularmente materia de controversias en el TEPJF. Así, por ejemplo, los mecanismos de selección de los consejeros electorales del IFE y de los magistrados del TEPJF mediante un sistema de cuotas partidistas, donde los partidos más influyentes imponen sus preferencias de manera flagrante y cínica. Lo mismo puede decirse de la inexistencia de una ley de partidos que, entre otras cosas, fije de manera clara y transparente mecanismos imparciales y regulares de fiscalización de sus recursos y activos, así como los mecanismos internos de selección de candidatos y dirigencias.

Resultan igualmente fuera de toda proporción y lógica los millonarios salarios de los funcionarios electorales (consejeros y ministros), que en lugar de precaverlos, como se pretende con tan redituables salarios, de cualquier tentación insana que empañe su imparcialidad, los vuelve sumisos y dóciles ante los partidos con tal de conservar sus privilegios. Se reproduce así en la arena electoral una de las prácticas más comunes y persistentes del viejo régimen: la simulación, o sea que se hace como que la democracia electoral requiere grandes inversiones para desarrollarse con imparcialidad, como si ésta pudiera comprarse. Cabe señalar que en la mayoría de las democracias modernas, los cargos electorales, además de ser temporales, o sea circunscritos a los tiempos de elecciones, suelen ser honorarios, o sea no remunerados. ¿Insólito? No, lógico, pues de otra manera se generarían 
todo tipo de suspicacias. Éstos sí son, pues, factores estructurales que ponen en peligro la equidad de una contienda.

\section{A manera de conclusión}

La transición democrática en México se ha caracterizado por su carácter tentativo y provisional. Esto se debe a que las elites políticas del régimen priísta nunca perdieron el control del proceso de apertura. Por el contrario, con las subsecuentes reformas electorales que promovieron desde la reforma política de 1977 hasta la reforma de 1996 sólo buscaban recobrar para el régimen alguna legitimidad que les permitiera mantenerse en el poder. Más que democratización lo que tuvimos fue un largo proceso de liberalización política, es decir, de flexibilización lenta y gradual de las restricciones a la competencia y la participación.

Sin embargo, la apertura restringida de la arena electoral generó nuevos equilibrios políticos y alternativas viables al partido del poder que en un contexto de crisis extrema terminaron por acotar al régimen y obligar a la elite gobernante a aceptar su derrota en las urnas. Como resultado tuvimos una transición por la vía de la alternancia, una transición sin pacto, lo que marca un hecho inédito en las transiciones democráticas y una problemática muy delicada para los gobiernos emergentes, que hasta cierto punto no tuvieron que enfrentar otros gobiernos en el mundo emanados de transiciones democráticas exitosas: el rediseño institucional y normativo del nuevo régimen sobre la base del régimen heredado, pero en un contexto altamente competitivo y sin una mayoría afín en el Congreso como para hacer avanzar dichas reformas con alguna certidumbre.

De ahí que México se encuentra después de la alternancia en una suerte de limbo, en el que los valores y las prácticas democráticas surgidas de la transición no pueden ser albergados de manera virtuosa en el entramado institucional y normativo vigente, que no es otro que el heredado del viejo régimen. En virtud de ello, el gran desafío para México en la actualidad es la reforma del Estado, que no es otra cosa que la reforma integral de la Constitución; una reforma que vuelva compatibles y coherentes a nuestras leyes e instituciones, por una parte, y las necesidades y exigencias de una auténtica democracia, por la otra. Huelga decir que mientras no se avance seriamente en la reforma del Estado, por más importantes que sean los logros en materia democrática, siempre serán insuficientes y en ocasiones hasta contradictorios con las leyes heredadas del pasado.

En este contexto, las elecciones federales de 2006 constituían en el papel una oportunidad óptima para apuntalar la joven democracia electoral del país. En efecto, si los comicios resultaban ejemplares en lo que a transparencia, par- 
ticipación, equidad e imparcialidad se refiere, se habría dado un paso decisivo hacia el firme establecimiento de las prácticas, valores, normas e instituciones electorales. Sin embargo, esto no ocurrió. Las elecciones presidenciales mostraron con tristeza que el sistema electoral mexicano adolecía de serias fallas e inconsistencias, pero sobre todo que no estaba preparado para enfrentar con madurez y solidez una contienda muy competida y reñida que dio por resultado un empate técnico entre dos de los candidatos. La consecuencia fue un proceso electoral sumamente impugnado que albergó en muchos mexicanos la sospecha sobre la legitimidad de las elecciones, al grado de que el país se encontró sumamente dividido y polarizado, con una democracia vapuleada y exhibida en sus muchas inconsistencias.

En los hechos, las instituciones y las leyes electorales vigentes no generaron la certidumbre institucional necesaria para unos comicios tan importantes. $Y$ aunque no existen indicios sólidos de un fraude o una manipulación deliberada de los resultados, quedó de manifiesto que en materia de democracia hay mucho por hacer aún, que tenemos una ley electoral insuficiente y poco congruente con las exigencias de una verdadera democracia.

Por ello, después de las elecciones de 2006 resultaba imperiosa para México una nueva reforma electoral que reforzara a nuestra muy cuestionada democracia electoral. Si la reforma no procedió antes fue porque las elecciones de la alternancia en el 2000 la vacunaron. Parecía entonces que habíamos encontrado la fórmula perfecta para organizar elecciones e incluso se creó la ficción de que nuestro modelo era exportable a otros países. Sin embargo, la diferencia entre los comicios del 2000 y del 2006 fueron simplemente algunos puntos de distancia entre los dos candidatos presidenciales más votados. Aquí no hay héroes ni villanos, simplemente circunstancias, y en el trasfondo la misma e insuficiente ley electoral, la de 1996. Sin embargo, en honor a la verdad, nadie quería verlo. Todos parecían encandilados con las bondades de la reforma electoral de 1996 y fuimos muy pocos los observadores que insistimos en esos años en las muchas incongruencias de la misma y advertimos que tarde o temprano debía modificarse de manera integral si se aspiraba a fortalecer nuestra democracia electoral. El hecho es que los castillos que se pretendieron construir eran de arena, y hoy los partidos han debido reconocer la fragilidad de origen de la legislación electoral. La pregunta que surge ahora es si las reformas electorales de 2007 cumplen o no con las necesidades y las exigencias de una auténtica democracia electoral, es decir, si está o no a la altura de lo que el país requiere o si constituye una reforma insuficiente a la que le sucederán inevitablemente nuevas reformas en el futuro, tan pronto como unos comicios muestren en la práctica sus puntos débiles. 
En mi opinión, como anticipé al inicio, si bien dichas reformas electorales contemplan avances importantes, son tantas las omisiones que no hay más remedio que aceptar el carácter tentativo y provisional de las mismas. En efecto, tal y como los partidos han presentado las modificaciones legales, a las reformas de "tercera generación", como muchos han llamado incorrectamente a esta reforma electoral, le sucederán en el futuro reformas de "cuarta", "quinta" y " $n$ " generaciones. La expresión es incorrecta porque sólo se puede hablar de reformas generacionales cuando los problemas que se buscan resolver con cada reforma son inéditos e imposibles de anticipar en el pasado. Obviamente, este no es el caso de México, pues aquí no ha habido ninguna temática considerada en las sucesivas reformas electorales cuya carga problemática no haya sido anticipada desde hace muchos años o incluso décadas. Lo que ha faltado más bien es la voluntad necesaria por parte de los actores políticos para introducir los cambios legales de una vez por todas, con una visión de largo plazo.

Por otra parte, no les falta razón a quienes argumentan que con estas reformas se da una vuelta de tuerca más hacia la afirmación de la partidocracia en México, o sea una desviación de la democracia, según la cual los partidos terminan monopolizando las actividades políticas, económicas y sociales, al querer canalizarlo todo por el cauce de la política institucional de los partidos. En los hechos, los primeros beneficiarios de esta reforma son los propios partidos mayoritarios, los cuales no ven afectados en lo más mínimo sus muchas prerrogativas e intereses al cobijo de la ley.

En su momento, la acalorada discusión pública sobre las muchas omisiones y despropósitos de la reforma electoral de 2007 nos hizo pensar a muchos que los legisladores introducirian los ajustes pertinentes antes de aprobar las reformas para que éstas no vulneraran derechos fundamentales o para que se impusiera la prudencia en muchos temas que suscitaban controversia. Lamentablemente, esto no ocurrió. Al final, los partidos mayoritarios se impusieron y, como suele ocurrir, la opinión pública fue simplemente ignorada por ellos. Con todo, es bueno que se reconozcan desde ahora los activos y los pasivos de esta reforma. Simplemente es cosa de esperar una nueva coyuntura favorable para que se den los acuerdos con un objetivo de miras más ambicioso que el que se pudo observar en esta ocasión. Sin embargo, las oportunidades son más bien escasas, y cada vez que se desperdicia una, se abona más a la incertidumbre y la desazón que a la estabilidad y la fortaleza de la democracia.

Que el gradualismo haya sido en el pasado reciente la estrategia dominante para avanzar en la transición tiene mucho sentido. Antes se buscaba preservar al régimen priísta a toda costa, como abrir cautamente la arena electoral. De hecho, la elite gobernante siempre pudo imponer a conveniencia sus preferencias 
CÉSAR CANSINO

y opciones en las reformas electorales, con una lógica minimalista más que maximalista. Pero esto que resulta obvio en el pasado no tiene sentido en el presente, una vez que hemos llegado a la democracia por la vía de la alternancia. Hoy no hay razones que justifiquen el gradualismo como estrategia para "perfeccionar" la ley electoral vigente. Si el minimalismo tuvo buenas razones en el pasado, poner al día nuestra democracia hoy para que funcione adecuadamente exige por parte de todos los actores políticos una estrategia maximalista, despojada de intereses inmediatistas o cortoplacistas.

En la actualidad, una vez que se ha cristalizado la alternancia y se ha dejado atrás al autoritarismo, no deberían caber posiciones timoratas y gradualistas para reformar la ley electoral. ¿Hasta cuándo? 